\title{
Effects of hot air drying temperature and tempering time on the properties of maize starch
}

\author{
Guangyue Ren ${ }^{1}$, Ledao Zhang ${ }^{2}$, Fanlian Zeng ${ }^{1}$, Yebei Li ${ }^{1}$, Linlin Li ${ }^{1}, X^{\prime}$ Duan $^{1 *}$ \\ (1. College of Food and Bioengineering, Henan University of Science and Technology, Luoyang 471023, Henan, China; \\ 2. School of Life Science and Technology, Inner Mongolia University of Science and Technology, Baotou 014010, \\ Inner Mongolia, China)
}

\begin{abstract}
Yellow maize as raw materials, hot air drying was used to reduce moisture content, and the tempering was implemented after drying. This study aimed to investigate the effects of hot air drying temperature and tempering time on the properties of maize starch. The wet milling was used to extract maize starch. Starch yield, protein content, amylose and amylopectin content, transparency and coagulation, solubility index and swelling power, color, pasting properties, and gelatinization properties were researched. The results showed that when the hot air temperature increased, the properties such as starch yield, amylopectin content, transparency, solubility, swelling power, whiteness decreased, and properties such as protein content and amylose content, coagulation, gelatinization temperature increased. Compared to drying temperature, tempering time has a less remarkable effect on the maize starch properties. The maize starch with better whiteness, solubility, swelling power could be obtained by adjusting tempering time.
\end{abstract}

Keywords: maize starch, hot air drying temperature, tempering time DOI: $10.25165 /$ j.ijabe.20201306.3362

Citation: Ren G Y, Zhang L D, Zeng F L, Li Y B, Li Linlin, Duan X. Effects of hot air drying temperature and tempering time on the properties of maize starch. Int J Agric \& Biol Eng, 2020; 13(6): 236-241.

\section{Introduction}

Maize is normally harvested at moisture content in the range of 23\%-30\% wet basis (w.b.). Research showed that microbial spoilage and deterioration reactions were greatly minimized after water was removed ${ }^{[1,2]}$

Hot-air drying is the most common method that is applied to the storage of agricultural products. The main drawbacks of the hot air drying method were undesirable physical, structural, chemical, organoleptic, and nutritional changes ${ }^{[3,4]}$.

Tempering was widely used in grain drying to improve quality and decrease drying $\operatorname{cost}^{[5]}$. To reduce crack in a kernel, tempering between drying passes is recommended in order to reduce moisture-induced stress ${ }^{[6,7]}$. The tempering time on rice fissuring was investigated by Dong et al. ${ }^{[8]}$ In their research, the fissure generation of three types of rough rice at different tempering time was studied. Their results indicated that tempering can prevent kernel fissuring. The tempering was adopted by Wilson et al.$^{[9]}$ to dry shelled maize with radiant heating. Their results indicated that the combined use of radiant heating and tempering was a rapid moisture removals method. The effect of

Received date: $2017-03-24 \quad$ Accepted date: $2020-08-31$

Biographies: Guangyue Ren, PhD, Professor, research interest: agricultural product drying technology, Email: guangyueyao@163.com; Ledao Zhang, PhD, lecturer, research interest: agricultural product drying technology, Email: nmzld2005@126.com; Fanlian Zeng, Graduate student, research interest: agricultural product drying technology; Yebei Li, Graduate student, research interest: agricultural product drying technology; Linlin $\mathbf{L i}, \mathrm{PhD}$, Lecturer, research interest: microwave-freeze drying mechanism and energy saving and quality loss reduction technology for agricultural products, rapid detection of agricultural products quality, E-mail: linlinli2020@126.com.

*Corresponding author: $\mathrm{Xu}$ Duan, $\mathrm{PhD}$, Professor, research interest: agricultural product drying technology. College of Food and Bioengineering, Henan University of Science \& Technology, No.263, Kaiyuan Road, Luoyang, Henan 471023, China. Tel: +86-379-64282342, Email: duanxu_dx@163.com. tempering on head rice yield during drying was studied by Sadeghi et al. ${ }^{[10]}$ In their research, the high drying conditions with drying temperature of $60^{\circ} \mathrm{C}$ and relative humidity of $17 \%$ and the low drying conditions with drying temperature of $40^{\circ} \mathrm{C}$ and relative humidity of $12 \%$ was investigated. Their results indicated that tempering had no significant effect on head rice yield under low drying conditions and could enhance head rice yield under high drying conditions.

In this study, the combined use of hot air drying and tempering was adopted to dry yellow maize. The content of starch in maize is about $70 \%-75 \%$, it is a valuable ingredient to the food industry, being widely used as a thickener, gelling agent, bulking agent and water retention agent ${ }^{[11]}$. The drying conditions have an obvious impact on the properties of starch, such as gelatinization, coagulation, pasting, granule and functional properties.

The effect of processing parameters on the pulsed-spouted microwave vacuum drying of puffed salted duck egg white/starch products was investigated by Wang et al. ${ }^{[12]}$ In their study, the moisture content of samples was dehydrated to about $12 \%$, and the color varied under different microwave powers. The effect of drying temperature on starch digestibility of germinated brown rice was investigated by Chungcharoen et al. ${ }^{[13]}$ Their research indicated that the amylose-lipid complexes occurred when the germinated samples were dried by a hot-air fluidized bed dryer at 130 or 150 degrees $\mathrm{C}$.

Malumba et al. ${ }^{[14]}$ indicated that high drying temperatures reduce the swelling capacities of starch granules and their solubility indexes during gelatinization. Heat-moisture treatment decreases starch solubility, swelling power, amylose leaching and peak viscosity, and increases the pasting temperature ${ }^{[15-18]}$.

In this study, the combined use of hot air drying and tempering was adopted to dry yellow maize, the wet milling was used to extract maize starch, the effect of hot air drying temperature and tempering time on the properties of maize starch was investigated, 
and the experimental strategy was provided for hot air-tempering drying used in maize.

\section{Materials and methods}

\subsection{Materials}

The yellow maize was field grown in 2014 at Luoyang (Henan Province). The maize was harvested with a moisture content of $33.86 \%$ (w.b.) and immediately stored at $-18^{\circ} \mathrm{C}$ in sealed plastic bags as maize samples. Before the drying experiment began, the maize with a sealed plastic bag was taken out and placed indoor until its temperature was not varied. The initial moisture content of the maize was $33.86 \%$ (w.b.). All chemicals and solvents used in the experiment were analytical grades.

\subsection{Drying and tempering experiments}

Maize samples were dried at a laboratory hot-air dryer with an air velocity of $0.43 \mathrm{~m} / \mathrm{s}$. Drying was carried out at temperatures of $60^{\circ} \mathrm{C}, 70^{\circ} \mathrm{C}, 80^{\circ} \mathrm{C}, 90^{\circ} \mathrm{C}$, and $100^{\circ} \mathrm{C}$, respectively. Drying was ended once the moisture content reached to $14 \%$ (w.b.). When drying was ended, tempering was begun in the dry oven at $35^{\circ} \mathrm{C}$ and the tempering time was $6 \mathrm{~h}, 8 \mathrm{~h}, 10 \mathrm{~h}, 12 \mathrm{~h}$, and $14 \mathrm{~h}$, respectively. The mass of every experiment was $100 \mathrm{~g}$. In the tempering step, the sample was kept in a closed jar to avoid moisture $\operatorname{loss}^{[19]}$. After that, the sample was stored at ambient temperature.

\subsection{Analysis of samples}

\subsubsection{Starch extraction rate}

Maize starch is extracted from dried maize samples following the method of the wet-milling process of Malumba et al. ${ }^{[20]}$ Starch was measured using the method of Reference [17]. The starch yield was determined by the following equation:

$$
\text { Starch yield }=\frac{\text { Mass of extractive starch }}{\text { Mass of corn starch in raw material }} \times 100 \%
$$

\subsubsection{Physicochemical properties of starches}

1) Chemical composition of starch

The contents of starch and residual protein were measured according to the AACC method $44-15 \mathrm{~A}^{[18]}$, the Ewers method (ISO 10520:1997), and the macro-Kjeldahl method, respectively.

2) Amylose and amylopectin content

Single wavelength colorimetry was used to determine the amylose and amylopectin content of the maize starch. A starch sample $(50 \mathrm{mg})$ was taken and mixed with $10 \mathrm{~mL} 0.5 \mathrm{~mol} / \mathrm{L}$ $\mathrm{KOH}$ in a volumetric flask of $100 \mathrm{~mL}$, then, heated and stirred in boiling water until the starch sample was completely dissolved, then, distilled water was added to the volumetric flask and maintain the total volume of solution was $100 \mathrm{~mL}$. Taken duplicate $15 \mathrm{~mL}$ solution in a volumetric flask and then added to two breakers equally, then taken duplicate $30 \mathrm{~mL}$ distilled water and added to two breakers equally, and then the $\mathrm{pH}$ of each solution in breaker was adjusted to 3.5 , with $0.1 \mathrm{~mol} / \mathrm{L} \mathrm{HCL}$. $0.5 \mathrm{~mL}$ of iodine reagent was added to one of the breakers, and both volume of solution in the two breakers were added to $100 \mathrm{~mL}$ by distilled water. After $20 \mathrm{~min}$, the solution with iodine reagent was a test sample and the solution without iodine reagent was a blank sample. The absorbance was measured at $620 \mathrm{~nm}$. The amylose content and amylopectin content were determined from a standard curve developed using amylose and amylopectin blends.

\section{3) Transparency and coagulation}

With constant stirring, $1 \%$ aqueous suspension of starch was heated in a water bath at $100^{\circ} \mathrm{C}$ for $30 \mathrm{~min}$ and the volume of starch solution was maintained constant. Then, the starch paste was cooled to indoor temperature and the absorbance of it was measured at $620 \mathrm{~nm}$ wavelength and the distilled water as blank. The transparency of maize starch was expressed by the absorbance of starch paste. $50 \mathrm{~mL} 1 \%$ aqueous suspension of starch was put into a measuring cylinder with stopper and placed $24 \mathrm{~h}$ without waggle at the indoor temperature, then, recorded the volume of the supernatant liquid and sediment layer. The coagulation property can be expressed as a percentage of the sediment layer volume of total paste volume.

4) Solubility index and swelling power

Solubility index (SOL) and swelling power (SP) were evaluated by the method of Mandala and Bayas ${ }^{[21]}$ with some modification. $50 \mathrm{~mL}$ centrifugal tubes that were filled with $2 \%$ aqueous suspension of starch were heated in a water bath at $90^{\circ} \mathrm{C}$ for $30 \mathrm{~min}$, and periodically middle shaking was applied to prevent the sedimentation of granules during heating. After heating, samples were centrifuged at $3000 \mathrm{r} / \mathrm{min}$ for $15 \mathrm{~min}$. Precipitated paste and supernatant were obtained, the mass of precipitated paste was $W_{1}$, the dry mass of precipitated paste and supernatant were $W_{2}$ and $W_{3}$, respectively. Dry mass was obtained at $105^{\circ} \mathrm{C}$ for $24 \mathrm{~h}$ in the dryer. The SOL is the percentage of dry mass in the supernatant to the dry mass of the whole starch sample $W_{0}$. SP is the ratio of precipitated paste to the dry mass of precipitated paste. The SOL and SP were defined as follows:

$$
\begin{gathered}
S O L=\frac{W_{3}}{W_{0}} \times 100 \% \\
S P(\mathrm{~g} / \mathrm{g})=\frac{W_{2}}{W_{1}}
\end{gathered}
$$

5) Color analysis

An X-rite Color I5 Colorimeter (X-Rite Inc., MI, USA) was used for color evaluation of samples. The measurements were taken at three different places on each starch sample to obtain the $L^{*}, a^{*}$, and $b^{*}$ values. $L^{*}$ represents black $(0)$ or white $(100), a^{*}$ represents redness $(+)$ or greenness $(-), b^{*}$ represents yellowness $(+)$ and blueness (-) degree, respectively. The whiteness index is defined as Equation (4) ${ }^{[22]}$ :

$$
\mathrm{WI}=100 \sqrt{\left(100-L^{*}\right)^{2}+a^{* 2}+b^{* 2}}
$$

where, WI is the whiteness index of samples; $L^{*}$ is brightness; $a^{*}$ is redness and greenness; $b^{*}$ is yellowness and blueness.

6) Pasting properties

The Brabender Visco Analyzer (803302, Germany) was used for pasting the evaluation of samples. Pasting properties were evaluated by the method of Sandhu and $\operatorname{Singh}^{[23]}$ with some modification. Viscosity profiles of starches samples were obtained by using an aqueous suspension of starch $(6 \%$, w/w; $460 \mathrm{~g}$ total weight) and a certain program. Certain heating and cooling cycle program was used, first, the aqueous suspension of starch was maintained at $30^{\circ} \mathrm{C}$, then heated to $95^{\circ} \mathrm{C}$ at $1.5^{\circ} \mathrm{C} / \mathrm{min}$, then, maintained at $95^{\circ} \mathrm{C}$ for $30 \mathrm{~min}$, then cooled from $95^{\circ} \mathrm{C}$ to $50^{\circ} \mathrm{C}$ at $1.5^{\circ} \mathrm{C} / \mathrm{min}$ and holded at $50^{\circ} \mathrm{C}$ for $30 \mathrm{~min}$. During measurement, the parameters such as pasting temperature, peak viscosity, trough viscosity (minimum viscosity at $95^{\circ} \mathrm{C}$ ), final viscosity (viscosity at $50^{\circ} \mathrm{C}$ ), breakdown viscosity (peak-trough viscosity) and setback viscosity (final-trough viscosity) were recorded.

7) Gelatinization properties

A differential scanning calorimeter (DSC, model 821e, Mettler Toledo, Switzerland) that was equipped with a thermal analysis data station was used to evaluate the gelatinization properties of starches samples by using the methods of Reference [23]. The starch $(3 \mathrm{mg}$ ) was accurately weighed into an aluminum DSC pan, $10 \mu \mathrm{L}$ of distilled water was added and the pan was hermetically 
sealed. The measurements were obtained when the pan was heated from $30^{\circ} \mathrm{C}$ to $110^{\circ} \mathrm{C}$ at a rate of $10^{\circ} \mathrm{C} / \mathrm{min}$ and the other empty pan was used as a reference. The main parameters obtained were onset temperature $\left(T_{0}\right)$, peak temperature $\left(T_{p}\right)$, end temperature $\left(T_{c}\right)$. The gelatinization properties of starch were calculated by the following equation ${ }^{[24]}$.

$$
S G(\%)=\left(1-\left[\frac{\Delta H}{\Delta H_{c}}\right]\right) \times 100
$$

where, $S G$ is the dimensionless quantity, which means the degree of gelatinization; $\Delta H$ and $\Delta H_{c}$ are the transition enthalpy of starches sample and the transition enthalpy of starches sample that is not subjected to the drying and tempering process.

\subsection{Statistical analysis}

All experiments were carried out three times. The data were subjected to statistical analysis using Orange8.5 (Minitab Inc., USA).

\section{Results and discussion}

\subsection{Starch yield and protein content}

The effect of drying temperatures, tempering time on starch yield and protein content are shown in Table 1. In Table 1, the starch yield decreases and protein content increases with the increase of drying temperature, this results are consistent with that of Mistry et al. ${ }^{[25]}$ The decreases in starch yield are caused by the partial gelatinization of maize starch and the protein denaturation during the hot air drying. The increases in protein content are agreed well with the postulation of Weller et al. ${ }^{[26]}$ They postulated that the high-temperature damage the endosperm protein and may prevent its solubilization during the steeping, and the starch could not set free during the wet-milling. A denatured protein may induce incomplete dissolve out of starch during the wet-milling, so starch and protein were difficult to separate.

Table 1 Starch yield and protein content under different drying temperature and tempering time

\begin{tabular}{ccc}
\hline Conditions & Starch yield/\% & Protein content $/ \%$ \\
\hline Undried & $68.26 \pm 1.17$ & $0.32 \pm 0.09$ \\
$60^{\circ} \mathrm{C}$ & $65.59 \pm 0.87$ & $0.53 \pm 0.02$ \\
$70^{\circ} \mathrm{C}$ & $62.37 \pm 2.00$ & $0.59 \pm 0.00$ \\
$80^{\circ} \mathrm{C}$ & $59.03 \pm 1.39$ & $0.63 \pm 0.01$ \\
$90^{\circ} \mathrm{C}$ & $55.44 \pm 1.74$ & $0.67 \pm 0.04$ \\
$100^{\circ} \mathrm{C}$ & $50.01 \pm 0.97$ & $0.77 \pm 0.01$ \\
Without tempering & $62.57 \pm 2.36$ & $0.45 \pm 0.01$ \\
$6 \mathrm{~h}$ & $62.57 \pm 2.98$ & $0.46 \pm 0.04$ \\
$8 \mathrm{~h}$ & $66.21 \pm 1.59$ & $0.47 \pm 0.03$ \\
$10 \mathrm{~h}$ & $70.41 \pm 2.60$ & $0.48 \pm 0.07$ \\
$12 \mathrm{~h}$ & $67.64 \pm 2.01$ & $0.52 \pm 0.03$ \\
$14 \mathrm{~h}$ & $66.25 \pm 3.07$ & $0.52 \pm 0.05$ \\
\hline
\end{tabular}

The starch yield increased first and then decreased with the increased of tempering time. The starch yield is the highest when tempering time was $10 \mathrm{~h}$ due to the internal moisture distribution of drying maize reached the best uniform state. In order to obtain a high starch yield, maintain tempering time at $10 \mathrm{~h}$ was a good method to increase the drying efficiency and utilization ratio of raw material. The protein content minorly increases with the increase of tempering time due to tempering enhancing the binding force between denatured protein and starch.

\subsection{Amylose and amylopectin content}

The effect of drying temperature and tempering time on the amylose and amylopectin content is shown in Figure 1. In Figure 1 , the solid line indicated drying temperature and the dash line indicated tempering time. It was shown that amylose content increased from $24.57 \%$ to $26.69 \%$ and the amylopectin content decreased from $75.43 \%$ to $73.31 \%$ when drying temperature increases from $60^{\circ} \mathrm{C}$ to $70^{\circ} \mathrm{C}$. The content of amylose and amylopectin has small changes during the drying temperature increases from $70^{\circ} \mathrm{C}$ to $100^{\circ} \mathrm{C}$. It was found that the drying temperature has an obvious effect on amylose and amylopectin content when drying temperature between $60^{\circ} \mathrm{C}$ and $70^{\circ} \mathrm{C}$. This suggested that amylopectin was more prone to degradation than amyloses during the drying temperature increases from $60^{\circ} \mathrm{C}$ to $70^{\circ} \mathrm{C}$. It is also shown that the amylose content increases slightly and the amylopectin content decreases slightly with the increase of tempering time from 6 to $14 \mathrm{~h}$.

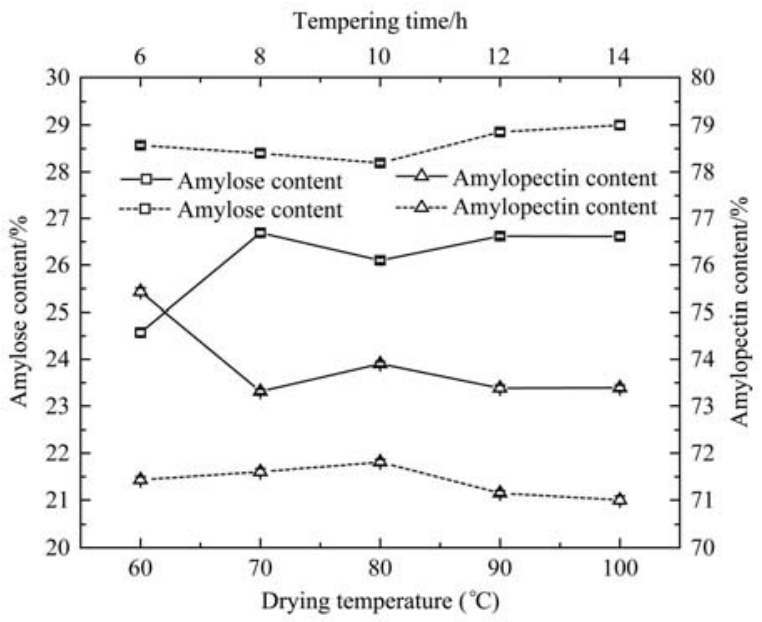

Figure 1 Effects of drying temperature and tempering time on the amylose and amylopectin content

\subsection{Transparency and retrogradation}

The transmittance and coagulation volume is used to reflect the transparency and retro-gradation of starch. The effect of drying temperature and tempering time on transmittance and coagulation volume is shown in Figure 2. In Figure 2, the solid line indicated drying temperature and the dash line indicated tempering time. The transmittance increases first and then decreases with the increases of tempering time. The coagulation volume decreases with the increases of tempering time. It suggested that transparency and retrogradation are closely related to the content of amylose.

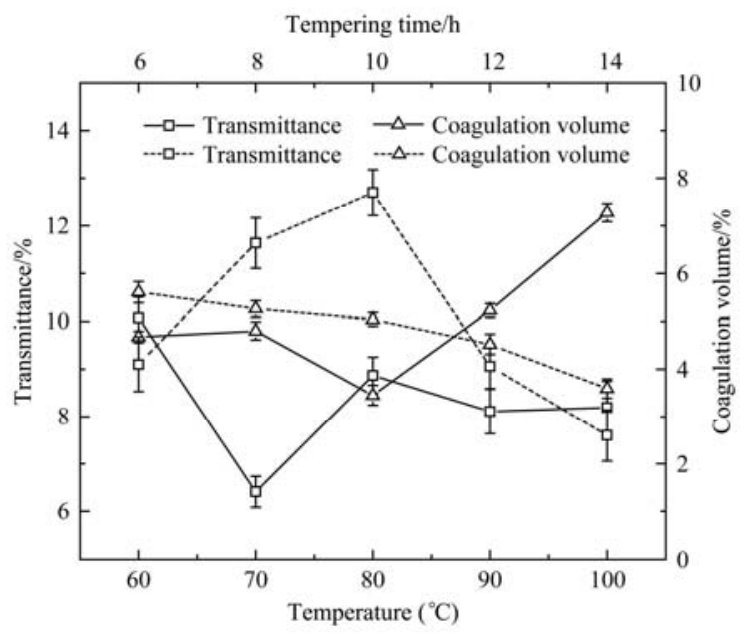

Figure 2 Effects of drying temperature and tempering time on transmittance and coagulation volume 


\subsection{Solubility index and swelling power}

The effect of drying temperature, tempering time on solubility and swelling power are shown in Figure 3. In Figure 3, the solid line indicated drying temperature and dash line indicated tempering time. It is shown that both solubility and swelling power decreases with the increase in drying temperature or tempering time. The value change of solubility and swelling power caused by drying temperature is larger than that caused by tempering time. It is suggested that drying temperature has a more obvious effect on the solubility and swelling power than tempering time. This result was consistent with the results of Wongsagonsup et al. ${ }^{[27]}$ and Kurakake et al. ${ }^{[28]}$, which indicated that heat treatment can make the starch particles lightly crosslinked in the amorphous regions ${ }^{[27]}$ and that the crosslinking can reduce the solubility and swelling power of $\operatorname{starch}^{[28]}$.

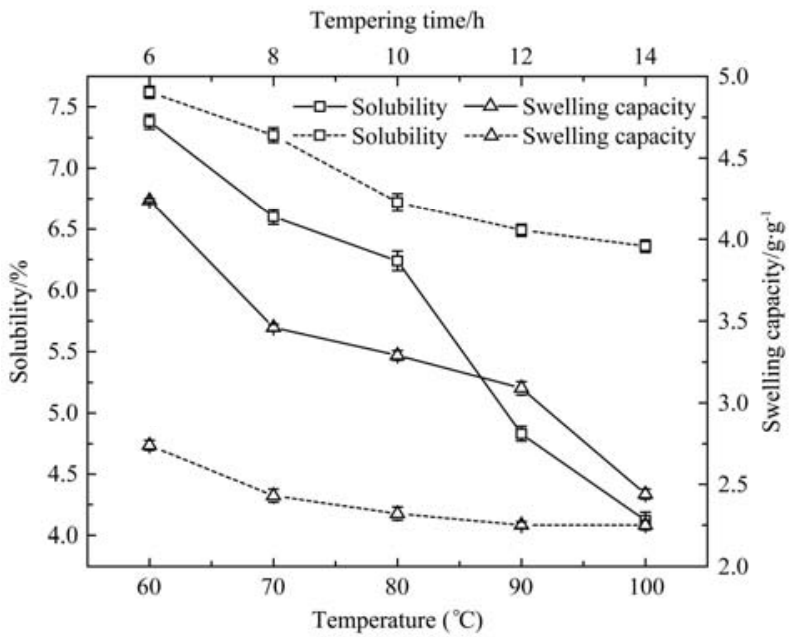

Figure 3 Effects of drying temperature and tempering time on solubility and swelling power

\subsection{Colors}

The WI, $L, a$, and $b$ values of starch under different drying temperature and tempering time are listed in Table 2. The WI decreased with the increase of drying temperature and increases first and then decreases with the increase of tempering time. The high $L$ value led to the high WI and the variation tendency of $L$ and WI was consistent The WI at drying temperature of $100^{\circ} \mathrm{C}$ is $2.63 \%$ fewer than that at drying temperature of $60^{\circ} \mathrm{C}$. It suggested that the change of the starch color was caused by non-enzymatic browning reactions due to high temperature. The $L$ value and WI are highest when the tempering time is $10 \mathrm{~h}$, and WI at tempering time of $10 \mathrm{~h}$ is more $2.97 \%$ than that at without tempering. The tempering time had no significant influence on color parameters. It suggested that a certain tempering time can be used to improve the WI of maize starch.

\subsection{Pasting properties}

The changes in the pasting properties of starch obtained from different drying temperature and tempering time are presented in Table 3. It can be observed that the pasting temperature increases with the increase in drying temperature, peak viscosity and final viscosity first increases and then decreases with the increase of drying temperature. These results were also reported in the research of Malumba et al. ${ }^{[29]}$ It is also showed that the breakdown value first increases and then decreases with the increase of drying temperature. These results have been reported in the research of Mistry et al. ${ }^{[25]}$ It suggested that high pre-treatments temperature prevented starch granules from breakdown. The setback value increases with the increase in drying temperature. It suggested that maize starch exhibited higher setback viscosity once the maize was subjected to higher temperatures.

Table 2 Effect of drying temperatures and tempering time on maize starch color

\begin{tabular}{ccccc}
\hline Condition & $L$ & $a$ & $b$ & WI \\
\hline Undried & 94.53 & 0.77 & 11.25 & 87.47 \\
$60^{\circ} \mathrm{C}$ & 95.52 & 0.96 & 10.01 & 88.99 \\
$70^{\circ} \mathrm{C}$ & 95.91 & 0.96 & 11.08 & 88.15 \\
$80^{\circ} \mathrm{C}$ & 95.07 & 0.88 & 12.08 & 86.92 \\
$90^{\circ} \mathrm{C}$ & 94.82 & 0.81 & 12.15 & 86.77 \\
$100^{\circ} \mathrm{C}$ & 94.77 & 0.78 & 12.19 & 86.71 \\
Without tempering & 95.35 & 1.23 & 12.60 & 86.51 \\
$6 \mathrm{~h}$ & 95.93 & 0.96 & 11.14 & 88.10 \\
$8 \mathrm{~h}$ & 96.85 & 0.86 & 11.10 & 88.43 \\
$10 \mathrm{~h}$ & 96.05 & 0.86 & 10.14 & 89.08 \\
$12 \mathrm{~h}$ & 96.11 & 0.74 & 10.93 & 88.37 \\
$14 \mathrm{~h}$ & 96.31 & 0.90 & 11.05 & 88.32 \\
\hline
\end{tabular}

Table 3 Pasting properties of maize starch at different drying temperature and tempering time

\begin{tabular}{cccccc}
\hline Condition & $\begin{array}{c}\text { Pasting } \\
\text { temperature } \\
/{ }^{\circ} \mathrm{C}\end{array}$ & $\begin{array}{c}\text { Peak } \\
\text { viscosity } \\
/ \mathrm{BU}\end{array}$ & $\begin{array}{c}\text { Final } \\
\text { viscosity } \\
/ \mathrm{BU}\end{array}$ & $\begin{array}{c}\text { Breakdown } \\
\text { value/BU }\end{array}$ & $\begin{array}{c}\text { Setback } \\
\text { value } \\
/ \mathrm{BU}\end{array}$ \\
\hline Undried & 67.7 & 930 & 1335 & 405 & 240 \\
$60^{\circ} \mathrm{C}$ & 69 & 1000 & 1529 & 602 & 257 \\
$70^{\circ} \mathrm{C}$ & 69.2 & 1324 & 1725 & 750 & 322 \\
$80^{\circ} \mathrm{C}$ & 70.7 & 1276 & 1630 & 677 & 326 \\
$90^{\circ} \mathrm{C}$ & 70.1 & 1251 & 1500 & 670 & 357 \\
$100^{\circ} \mathrm{C}$ & 72.1 & 1027 & 1431 & 534 & 377 \\
Without tempering & 68.8 & 1153 & 1700 & 810 & 394 \\
$6 \mathrm{~h}$ & 68.9 & 1090 & 1679 & 766 & 336 \\
$8 \mathrm{~h}$ & 69.1 & 945 & 1567 & 694 & 347 \\
$10 \mathrm{~h}$ & 69 & 914 & 1538 & 672 & 351 \\
$12 \mathrm{~h}$ & 69 & 740 & 1392 & 600 & 387 \\
$14 \mathrm{~h}$ & 69 & 587 & 1357 & 592 & 446 \\
\hline
\end{tabular}

Peak viscosity, final viscosity, and breakdown value decreases with the increase of tempering time. The phenomenon of peak viscosity and breakdown value decrease has been reported by Malumba ${ }^{[29]}$. They indicated that this phenomenon owed to starch granules was hard to breakdown. The decrease in the breakdown value maybe showed that the tempering steps helped to increase starch granules. It was shown that setback value increased when tempering time increased from $6 \mathrm{~h}$ to $14 \mathrm{~h}$. According to the reported of Lan et al. ${ }^{[30]}$, the amount of soluble amylose, starch particle size and unbroken starch granule swelling may affect the setback values.

It is also observed that both the increases in drying temperature and tempering time could enhance pasting temperatures. This result agreed well with the reports that the starch gelatinization and the formation of amylose-lipid complexes lead the higher pasting temperatures ${ }^{[31]}$ during subjected to drying and tempering steps.

\subsection{Thermal analysis}

The thermal properties of maize starch after drying and tempering are listed in Table 4. It includes the gelatinization temperatures (onset temperature $T_{0}$, peak temperature $T_{p}$, and end temperature $T_{e}$ ), enthalpy of gelatinization $(\Delta H)$ and the degree of gelatinization (SG). The gelatinization temperatures were controlled by the amorphous region around the starch granule. 
Table 4 DSC data of maize starches

\begin{tabular}{ccccccc}
\hline Condition & $T_{0} /{ }^{\circ} \mathrm{C}$ & $T_{p} /{ }^{\circ} \mathrm{C}$ & $T_{e} /{ }^{\circ} \mathrm{C}$ & $T_{e}-T_{0} /{ }^{\circ} \mathrm{C}$ & $\Delta H / \mathrm{J} \cdot \mathrm{g}^{-1}$ & $\mathrm{SG} / \%$ \\
\hline Undried & 62.8 & 64.6 & 69.1 & 6.3 & 13.76 & 0 \\
$60^{\circ} \mathrm{C}$ & 63.7 & 68.9 & 71.1 & 7.4 & 13.40 & 2.73 \\
$70^{\circ} \mathrm{C}$ & 65.1 & 73.5 & 72.5 & 7.4 & 13.00 & 5.57 \\
$80^{\circ} \mathrm{C}$ & 70.3 & 74.5 & 77.8 & 7.5 & 12.90 & 7.31 \\
$90^{\circ} \mathrm{C}$ & 70.9 & 74.9 & 78.7 & 7.8 & 11.52 & 16.30 \\
$100^{\circ} \mathrm{C}$ & 71.4 & 75.8 & 80.0 & 8.6 & 11.60 & 15.72 \\
Without tempering & 67.8 & 72.1 & 76.3 & 8.5 & 11.70 & 15.07 \\
$6 \mathrm{~h}$ & 68.6 & 72.4 & 75.9 & 7.3 & 11.80 & 15.43 \\
$8 \mathrm{~h}$ & 69.1 & 72.7 & 76.3 & 7.2 & 11.68 & 15.13 \\
$10 \mathrm{~h}$ & 69.3 & 72.9 & 78.4 & 9.1 & 12.01 & 12.81 \\
$12 \mathrm{~h}$ & 69.6 & 73.2 & 77.6 & 8.0 & 12.14 & 11.87 \\
$14 \mathrm{~h}$ & 68.8 & 72.7 & 76.7 & 7.9 & 12.07 & 12.32 \\
\hline
\end{tabular}

From Table 4 , the onset temperature $T_{0}$ increases with the increase in drying temperature. The onset temperature $T_{0}$ increased first and then decreases with the increase of tempering time. The effect of drying temperature on onset temperature $T_{0}$ is more remarkable than that of tempering time. Peak temperature $T_{p}$ and end temperature $T_{e}$ increases significantly with the increase of drying temperature. Peak temperature $T_{p}$ and end temperature $T_{e}$ first increases and then decreases with the increase of tempering time, and the amplitude of augmenting and reduction is small. $T_{e}-T_{0}$ reflects the degree of diversification between starch granules, and the larger of $T_{e}-T_{0}$, the greater degree of diversification between starch granules. The impact degree of drying temperature and tempering time on $T_{e}-T_{0}$ was similar. The enthalpy required for melting starch $\Delta \mathrm{H}$ decreased with the increase in drying temperature and tempering time has little effect on $\Delta H$. The degree of starch gelatinization $\mathrm{SG}$ increases remarkably when the drying temperature increases from $60^{\circ} \mathrm{C}$ to $100^{\circ} \mathrm{C}$. The SG first decreases and then increases with the increase of tempering time and there is only little variation when tempering time is between $6 \mathrm{~h}$ and $8 \mathrm{~h}$.

\section{Conclusions}

The hot air drying and tempering was used to reduce moisture content in yellow maize. The effect of drying temperature and tempering time on the properties of maize starch was researched in this paper. The wet milling was used to obtain maize starch from maize samples. The maize starch properties, such as starch yield, protein content, amylose and amylopectin content, transparency and coagulation, solubility index and swelling power, color, pasting properties, and gelatinization properties were investigated in detail. The results showed that the hot air temperature had a more obvious effect on maize properties than tempering time. The increase in dry temperature lead to the increase of protein content, amylose content, coagulation, gelatinization temperature, and lead to the decrease of starch yield, amylopectin content, transparency, solubility, swelling power, whiteness. Maintain the tempering time at $10 \mathrm{~h}$ can obtain maize starch with the largest starch yield and transparency. The increase in the tempering time leads to slight increase in amylose content and a decrease of amylopectin, solubility, swelling power, coagulation volume.

\section{Acknowledgements}

This work was financially supported by the National Natural Science Foundation of China (Grant No. 31271972, No. 31671907, No. 52006109) and the University Science and Technology
Innovation Team Support Plan of Henan Province of China in 2016 (16IRTSTHN009).

\section{[References]}

[1] Wang H L, Lu T, Zhang Q G. Drying characteristics of biological porous media during convective drying. Int J Agric \& Biol Eng, 2016; 9(5): 194-207.

[2] Xi H H, Liu Y H, Guo L G, Hu R R. Effect of ultrasonic power on drying process and quality properties of far-infrared radiation drying on potato slices. Food Science and Biotechnology, 2020; 29(1): 93-101.

[3] Liu Y H, Zeng Y, Wang Q, Sun C Y, Xi H H. Drying characteristics, microstructure, glass transition temperature, and quality of ultrasound-strengthened hot air drying on pear slices. Journal of Food Processing and Preservation, 2019; 43(3): e13899. doi: 10.1111/jfpp. 13899.

[4] Duan L L, Duan X, Ren G Y. Structural characteristics and texture during the microwave freeze drying process of Chinese yam chips. Drying Technology, 2020; 38(7): 928-939.

[5] Golmohammadi M, Rajabi-Hamane M, Hashemi S J. Optimization of drying-tempering periods in a paddy rice dryer. Drying Technology, 2012 30(1): 106-113.

[6] Poomsa-ad N, Terdyothin A, Prachayawarakorn S, Soponronnarit S. Investigations on head-rice yield and operating time in the fluidised-bed drying process: experiment and simulation. Journal of Stored Products Research, 2005; 41(4): 387-400.

[7] Tuyen T T, Truong V, Fukai S, Bhandari B. Effects of high-temperature fluidized bed drying and tempering on kernel cracking and milling quality of Vietnamese rice varieties. Drying Technology, 2009; 27(3): 486-494.

[8] Dong R J, Lu Z H, Liu Z Q, Koide S; Cao W. Effect of drying and tempering on rice fissuring analysed by integrating intra-kernel moisture distribution. Journal of Food Engineering, 2010; 97(2): 161-167.

[9] Wilson S A, Atungulu G G, Couch A, Sadaka S. Radiant heating and tempering treatments for improving rate of moisture removal during drying of shelled corn. Applied Engineering in Agriculture, 2015; 31(5): 799-808.

[10] Sadeghi M, Nasrnia E, Masoumi A A, Hemmat A. Head rice yield response to low and high drying and tempering conditions. International Agrophysics, 2013; 27(2): 219-223.

[11] Singh N, Singh J, Kaur L, Sodhi N S, Gill B S. Morphological, thermal and rheological properties of starches from different botanical sources. Food Chemistry, 2003; 81(2): 219-231.

[12] Wang T, Zhang M, Fang Z X, Liu Y P. Effect of processing parameters on the pulsed-spouted microwave vacuum drying of puffed salted duck egg white/starch products. Drying Technology, 2016; 34(2): 206-214.

[13] Chungcharoen T, Prachayawarakorn S, Tungtrakul P, Soponronnarit S. Effects of germination process and drying temperature on Gamma-Aminobutyric Acid (GABA) and starch digestibility of germinated brown rice. Drying Technology, 2014; 32(6): 742-753.

[14] Malumba P, Massaux C, Deroanne C, Masimango T, Béra F. Influence of drying temperature on functional properties of wet-milled starch granules. Carbohydrate Polymers, 2009; 75(2): 299-306.

[15] Wu M, Liu Y. Wang L J, Li D. Effects of extrusion parameters on rheological properties, chromatism, protein solubility and microstructure of flaxseed-corn mixture. Int J Agric \& Biol Eng, 2015; 8(6): 89-98.

[16] Liu W W, Xue J, Cheng B J, Zhu S W, Ma Q, Ma H. Anaerobic biodegradation, physical and structural properties of normal and high-amylose maize starch films. Int J Agric \& Biol Eng, 2016; 9(5): 184-193.

[17] Pinto V Z, Vanier N L, Klein B, de Rosa Zavareze E, Elias M C, Gutkoski L C, et al. Physicochemical, crystallinity, pasting and thermal properties of heat moisture treated pinhão starch. Starch-Stärke, 2012; 64(11): $855-863$.

[18] Sui Z Q, Shah A, BeMiller J N. Crosslinked and stabilized in-kernel heat-moisture-treated and temperature-cycled normal maize starch and effects of reaction conditions on starch properties. Carbohydrate Polymers, 2011; 86(4): 1461-1467.

[19] Donludee J, Somkiat P, Warunee V, Patcharee T, Somchart S. Effects of drying temperature and tempering time on starch digestibility of brown fragrant rice. Journal of Food Engineering, 2008; 86(2): 251-258.

[20] Malumba P, Janas S, Masimango T, Sindic M, Deroanne C, Béra F. Influence of drying temperature on the wet-milling performance and the proteins solubility indexes of corn kernels. Journal of Food Engineering, 2009; 95(3): 393-399. 
[21] Mandala I G, Bayas E. Xanthan effect on swelling, solubility and viscosity of wheat starch dispersions. Food Hydrocolloids, 2004; 18(2): 191-201.

[22] Rhim J W, Wu Y X, Weller C L, Schnepf M. Physical characteristics of a composite film of soy protein isolate and propyleneglycol alginate. Journal of Food Science, 1999; 64(1): 149-152.

[23] Sandhu K S, Singh N. Some properties of corn starches II: Physicochemical, gelatinization, retrogradation, pasting and gel textural properties. Food Chemistry, 2007; 101(4): 1499-1507.

[24] Fu Z Q, Wang L J, Li D, Adhikari B. Effects of partial gelatinization on structure and thermal properties of corn starch after spray drying. Carbohydrate Polymers, 2012; 88(4): 1319-1325.

[25] Mistry A H, Wu X, Eckhoff $\mathrm{S} \mathrm{R}$, Litchfield J B. Wet-milling characteristics of high-temperature, high-humidity maize. Cereal Chemistry, 1993; 70(3): 360-361.

[26] Weller C, Paulsen M R, Steinberg M P. Correlation of starch recovery with assorted quality factors of four corn hybrids. Cereal Chemistry,
1988; 65(5): 392-397.

[27] Wongsagonsup R, Varavinit S, BeMiller J N. Increasing slowly digestible starch content of normal and waxy maize starches and properties of starch products. Cereal Chemistry, 2008; 85(6): 738-745.

[28] Kurakake M, Akiyama Y, Hagiwara H, Komaki T. Effects of cross-linking and low molecular amylose on pasting characteristics of waxy corn starch. Food Chemistry, 2009; 116(1): 66-70.

[29] Malumba P, Janas S, Roiseux O. Comparative study of the effect of drying temperatures and heat-moisture treatment on the physicochemical and functional properties of corn starch. Carbohydrate Polymers, 2010; 79(3): 633-641.

[30] Lan H, Hoover R, Jayakody L. Impact of annealing on the molecular structure and physicochemical properties of normal, waxy, and high amylose bread wheat starches. Food Chemistry, 2008; 111(9): 663-675.

[31] Jaisut D, Prachayawarakorn S, Varanyanond W. Effects of drying temperature and tempering time on starch digestibility of brown fragrant rice. Journal of Food Engineering, 2008; 86(2): 251-258. 